\title{
Standard Test to Measure Knowledge of Groundnut Farmers on Sustainable Cultivation Practices
}

\author{
N. Srividya Rani ${ }^{1 *}$, T. Lakshmi ${ }^{1}$, P. V. Sathya Gopal ${ }^{2}$, N. Vani ${ }^{3}$ and B. Ravindra Reddy ${ }^{4}$ \\ ${ }^{1}$ Department of Agricultural Extension, ${ }^{3}$ Department of Economics, ${ }^{4}$ Department of \\ Statistics and Mathematics, S.V. Agricultural College, Tirupati, A.P., India \\ ${ }^{2}$ Department of Agril Extension, College of Agriculture, Bapatla, India \\ *Corresponding author
}

\section{Keywords}

Knowledge test,

Sustainable

cultivation

practices,

Article Info

Accepted:

15 December 2019

Available Online:

20 January 2020

\section{A B S T R A C T}

This study aimed at determining the farmers knowledge on sustainable cultivation practices in groundnut. 81 items on knowledge were selected from a large number of item pool collected based on standard criteria and in consultation with scientists of RARS, Tirupati, Subject Matter Specialists, trainers, extensionists of Acharya N.G.Ranga Agricultural University. Finally, 39 items were selected after following the statistical procedures for the construction of standard knowledge test.

\section{Introduction}

Indian agriculture in the present era in mainly dependent on rainfed agriculture. To overcome the problems of rainfed agriculture sustainable agriculture came into lime light. This concept in our study was presently applied on one of the major oil seed crops of the Rayalaseema region of Andhra Pradesh i.e. groundnut.

The yield of this crop depends on the knowledge and adoption of the cultivation practices in groundnut which are sustainable. Hence an effort was made to develop the standard knowledge test to appraise the knowledge levels of the farmers. In spite of several extension efforts taken by the scientists, extensionists and field workers farmers are not having knowledge about the exact cultivation practices in groundnut which are sustainable. This necessitated the development of a standard test for the accurate assessment of the knowledge levels of the farmers.

\section{Materials and Methods}

The present investigation was conducted in three villages viz., Mitturu and 
Khammakandriga of Ramachandrapuram mandal and Chenchugudi village from Vedurukuppammandal of Chittoor district of Andhra Pradesh during April 2016. A sample of 60 respondents were selected randomly i.e. 20 from each village.

The knowledge test was developed by employing following methodology and the standardization of the test items were presented below.

\section{Collection and framing of knowledge items}

The content of the test was composed of questions called items. A comprehensive list (81) of knowledge questions on recommended production technology with special emphasis on sustainable cultivation practices in groundnut was prepared on the basis of extensive review of literature and consultation with scientists of ANGRAU, RARS, Tirupati, subject matter specialists, field extension workers and State Department of Agriculture, Andhra Pradesh. By using the above criteria, 81 items were selected for developing knowledge test after careful editing and by subjecting them to expert scrutiny.

\section{Selection of items}

The selection of items was done on the basis of the following criteria.

Response to items should promote thinking than routine memorization

They should differentiate the well-informed respondent from less informed and should have certain difficulty value.

The items included should cover all areas of knowledge about production technology.

\section{Form of questions}

The items selected for the construction of knowledge test on production technology with special emphasis on Integrated Crop Management practices on groundnut crop were framed in the objective form of questions namely multiple choice, fill in the blanks, yes or no and true or false.

\section{Pre-testing}

Pre testing of the items was done as suggested by Gonard (1948). The items selected for the knowledge test were pre-tested separately by administering the items to 60 respondents. Care was taken to see that 60 respondents selected for this purpose were outside the main sample of the study.

\section{Item analysis}

The Item analysis was carried out to yield two kinds of information viz., indices of 'Item difficulty' and 'Item discrimination'. The index of item difficulty indicates the extent to which an item was difficult.

The later provides information on how well an item measures or discriminates a wellinformed respondent from poorly informed respondent.

To analyse the items undertaken for item analysis, each response for multiple choice, fill in the blanks, true or false and yes or no, questions were given a score of one and zero for correct and incorrect responses, respectively. After computing the individual total score for the 60 respondents, the respondents were arranged in descending order based on total score.

These 60 respondents were then divided into 6 equal groups named as $\mathrm{G}_{1}, \mathrm{G}_{2}, \mathrm{G}_{3}, \mathrm{G}_{4}, \mathrm{G}_{5}$, and $\mathrm{G}_{6}$ with 10 respondents in each group. For item analysis, the middle two groups $\mathrm{G}_{3}$ and $\mathrm{G}_{4}$ were eliminated keeping only 4 extreme groups, with high scores namely, $\mathrm{G}_{1}$ and $\mathrm{G}_{2}$ and low scores namely, $\mathrm{G}_{5}$ and $\mathrm{G}_{6}$.

After getting the four extreme groups with high and low scores the data of correct 
responses for each of 81 items were tabulated for each of these four groups (Bloom et al., 1956.)

\section{Selection of the items for the final test}

\section{Item difficulty index (P)}

The item difficulty index for each of the 81 items was calculated as the percentage of respondents answering an item correctly was computed by using the following formula

Item difficulty index $(\mathrm{P})$

No. of respondents

$$
=\stackrel{\text { answered correctly }}{X} 100
$$

Total no. of respondents

The items with difficulty index ranging from 20 to 80 were considered for final selection for the knowledge test to avoid extremely simple and difficult items.

\section{Discrimination index $\left(E^{1 / 3}\right)$}

Discrimination index of each of the items were computed by using the following formula.

$E^{1 / 3}=\frac{\left(S_{1}+S_{2}\right)-\left(S_{5}+S_{6}\right)}{N / 3}$

Where, $S_{1}, S_{2}, S_{5}$ and $S_{6}$ are the frequencies of correct answers in groups $\mathrm{G}_{1}, \mathrm{G}_{2}, \mathrm{G}_{5}$ and $\mathrm{G}_{6}$, respectively and $\mathrm{N}$ is the total number of respondents in the sample selected for items analysis (60). The value of the discrimination index for the knowledge items on production technology with special emphasis on sustainable cultivation practices in groundnut ranging from 0.2 to 0.8 were considered for the final selection of knowledge test for same reasons explained under item difficulty index.

\section{Point biserial correlation (rpbis)}

Point biserial correlation (rpbis) is the test validation in which the criterion of validity is considered to be internally consistent. That is, the relationship of the total score to a dichotomized response to any given item. An item by item computation of point biserial correlation was calculated by using the formula suggested by Garrett (1966).

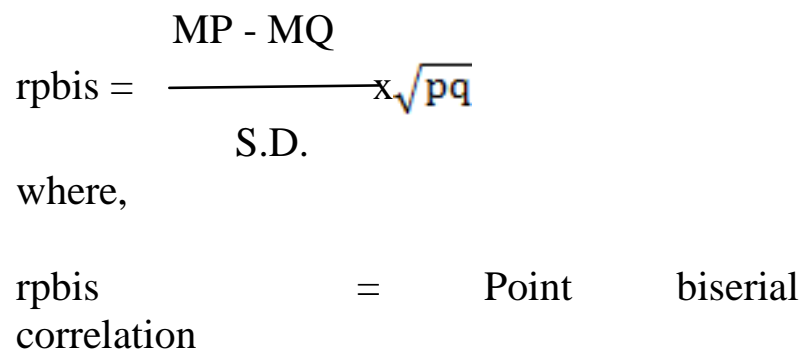

MP = Mean of the scores of the respondents who answered the item correctly (or)

$\mathrm{Mp}=\frac{\text { Sum of the total of } \mathrm{XY}}{\text { Total number of correct answers }}$

$\mathrm{Mq}=$ Mean of the total scores of the respondents who answered the item incorrectly (or)

$$
\mathrm{Mq}=\frac{\text { Sum total of } \mathrm{X}-\text { Sum total of XY }}{\text { Total number of wrong answers }}
$$

$\mathrm{SD}=$ Standard deviation of the entire sample

$\mathrm{p}=$ Proportion of the respondents giving correct answer to the item

$\mathrm{q}=$ Proportion of the respondents giving incorrect answer to the item (or)

$q=1-p$

$X=$ Total score of the respondent for all the items

$\mathrm{Y}=$ Response of the individual for the items

$($ Correct $=1 ;$ Incorrect $=0)$ 
$\mathrm{XY}=$ Total score of the respondent multiplied by the response of the individual to the item.

Items having significant point biserial correlation, either at 1 per cent or 5 per cent level were selected for the final test of the knowledge (Table 1).

$\mathrm{t}=\underline{\operatorname{rpbis} \sqrt{ } \mathrm{N}-2}$

$\sqrt{1-\text { rpbis }^{2}}$

The resulting co-efficient is a product moment correlation co-efficient

\section{Total items selected}

Out of 81 items 39 items were finally selected based on the following criteria.

Items with difficulty level indices ranging from 20 to 80 .

Items with discrimination indices ranging from 0.20 to 0.80 .

Items having point biserial correlation either at 1 per cent or 5 per cent level

All important components of the recommendations have been covered. The questions were prepared in such a way that no important component has been left out.

The finally selected 39 knowledge test items comprised of four types of questions viz., Multiple choice (4 Nos.), Fill in the blanks (15 Nos.), Yes or No (8 Nos.) and True or False (12 Nos.)

\section{Reliability of the test}

Split half method was used to compute the reliability of the test. The test administered to 60 respondents was divided into two halves based on odd and even numbered statements. Two sets of scores were derived on half forms of the test and the scores were correlated for the reliability of the half test. The selfcorrelation of the whole test was then estimated by the Spearman Brown prophecy Formula. The calculated value of reliability Co-efficient (0.78) for whole test found to be highly significant, hence it was concluded that test was reliable.

\section{Validity of the test}

Knowledge test developed on production technology with special emphasis on Sustainable cultivation practices in groundnut was subjected to content and construct validity. The construct validity of the test items was tested by the method of point biserial correlation ( $\mathrm{r}$ pbis). The items have significant values at $1 \%$ and $5 \%$ level indicated the validity of the test.

The content validity of knowledge test was derived from a large pool of test items separately. The test items represented the whole universe of production technology with special emphasis on Sustainable cultivation practices in groundnut.

It was thus assumed that the scores obtained by administering the knowledge test of this study measures what intended to measure.

\section{Results and Discussion}

The results of the knowledge test obtained were as follows in Table-1. Out of 81 items, 39 items were finally selected based on item discrimination index and ' $\mathrm{t}$ ' values obtained.

Each of the 39 items in the knowledge test were administered to the respondents in Telugu language and their respondents were recorded in the form of correct and incorrect answers. The correct answer was assigned a weightage of 1 and a weightage of 0 was assigned to incorrect answer. 
Table.1 Difficulty, Discrimination and Point biserial correlation for knowledge test items

\begin{tabular}{|c|c|c|c|c|c|c|c|c|c|}
\hline \multirow[t]{2}{*}{ S.No. } & \multicolumn{4}{|c|}{$\begin{array}{l}\text { Frequencies of } \\
\text { correct answer of } \\
\text { respondents in four } \\
\text { extreme groups }\end{array}$} & \multirow[t]{2}{*}{$\begin{array}{c}\text { Totalfrequencies } \\
\text { of correct } \\
\text { answers by all six } \\
\text { groups (n=60) }\end{array}$} & \multirow[t]{2}{*}{$\begin{array}{l}\text { Difficulty index } \\
P(\% \text { of } \\
\text { respondents } \\
\text { giving correct } \\
\text { responses })\end{array}$} & \multirow[t]{2}{*}{$\begin{array}{l}\text { Discrimination } \\
\text { index }\left(\mathbf{E}^{1 / 3}\right)\end{array}$} & \multirow[t]{2}{*}{$\begin{array}{c}\text { Point } \\
\text { biserial } \\
\text { correlation } \\
\text { (rpbis) }\end{array}$} & \multirow[t]{2}{*}{$\begin{array}{c}\text { 't' } \\
\text { Values }\end{array}$} \\
\hline & $\mathrm{G}_{1}$ & $\mathrm{G}_{2}$ & $\mathrm{G}_{5}$ & $\mathrm{G}_{6}$ & & & & & \\
\hline 1 & 10 & 10 & 10 & 10 & 60 & 100.00 & 0.00 & 0.01 & 0.0200 \\
\hline 2 & 10 & 9 & 10 & 10 & 57 & 95.00 & -0.05 & -0.016 & -0.1250 \\
\hline 3 & 10 & 10 & 8 & 8 & 54 & 90.00 & 0.20 & 0.077 & 0.5936 \\
\hline 4 & 10 & 10 & 6 & 5 & 47 & 78.33 & 0.45 & 0.320 & $2.5723^{*}$ \\
\hline 5 & 9 & 9 & 7 & 5 & 45 & 75.00 & 0.30 & 0.449 & $3.8269^{* *}$ \\
\hline 6 & 9 & 5 & 6 & 2 & 31 & 51.67 & 0.30 & 0.261 & $2.0590^{*}$ \\
\hline 7 & 10 & 10 & 6 & 6 & 43 & 71.66 & 0.40 & 0.294 & $2.3487^{*}$ \\
\hline 8 & 6 & 9 & 6 & 5 & 42 & 70.00 & 0.20 & 0.342 & $2.7754^{* *}$ \\
\hline 9 & 9 & 8 & 5 & 6 & 46 & 76.67 & 0.30 & 0.254 & $1.9998^{*}$ \\
\hline 10 & 9 & 8 & 7 & 9 & 50 & 83.33 & 0.05 & 0.009 & 0.0751 \\
\hline 11 & 9 & 8 & 5 & 6 & 45 & 75.00 & 0.30 & 0.456 & $3.9021^{* *}$ \\
\hline 12 & 9 & 10 & 9 & 8 & 52 & 86.67 & 0.10 & 0.076 & 0.5835 \\
\hline 13 & 9 & 9 & 7 & 4 & 43 & 71.67 & 0.35 & 0.437 & $3.7000^{* *}$ \\
\hline 14 & 9 & 7 & 8 & 8 & 46 & 76.67 & 0.00 & 0.010 & 0.0821 \\
\hline 15 & 9 & 9 & 7 & 7 & 48 & 80.00 & 0.20 & 0.301 & $2.4038^{*}$ \\
\hline 16 & 6 & 5 & 1 & 5 & 26 & 43.33 & 0.25 & 0.279 & $2.2204^{*}$ \\
\hline 17 & 9 & 10 & 9 & 8 & 52 & 86.67 & 0.10 & 0.0004 & 0.1622 \\
\hline 18 & 10 & 9 & 8 & 3 & 48 & 80.00 & 0.40 & 0.401 & 3.3356 ** \\
\hline 19 & 8 & 5 & 6 & 3 & 32 & 53.33 & 0.20 & 0.323 & $2.5992^{* *}$ \\
\hline 20 & 10 & 10 & 10 & 10 & 60 & 100.00 & 0.00 & 0.0001 & 1.4121 \\
\hline 21 & 10 & 10 & 7 & 10 & 56 & 93.33 & 0.15 & 0.055 & 0.4208 \\
\hline 22 & 8 & 10 & 7 & 8 & 50 & 83.33 & 0.15 & 0.162 & 1.2502 \\
\hline 23 & 10 & 10 & 5 & 8 & 47 & 78.33 & 0.35 & 0.344 & $2.7901^{* *}$ \\
\hline 24 & 9 & 7 & 7 & 3 & 43 & 71.67 & 0.30 & 0.532 & $4.7849^{* *}$ \\
\hline 25 & 10 & 10 & 3 & 4 & 40 & 66.67 & 0.65 & 0.091 & 0.6991 \\
\hline 26 & 7 & 7 & 8 & 6 & 38 & 63.33 & 0.00 & 0.019 & 0.1454 \\
\hline 27 & 9 & 10 & 9 & 7 & 54 & 90.00 & 0.15 & 0.057 & 0.4348 \\
\hline 28 & 7 & 10 & 7 & 5 & 45 & 75.00 & 0.25 & 0.256 & $2.0168^{*}$ \\
\hline 29 & 10 & 5 & 5 & 4 & 36 & 60.00 & 0.30 & 0.391 & 3.2353 $^{\text {** }}$ \\
\hline 30 & 10 & 9 & 6 & 8 & 48 & 80.00 & 0.25 & 0.351 & $2.8547^{* *}$ \\
\hline 31 & 10 & 9 & 5 & 7 & 45 & 75.00 & 0.35 & 0.293 & 2.3334 \\
\hline 32 & 8 & 8 & 8 & 7 & 49 & 81.67 & 0.05 & 0.020 & 0.1541 \\
\hline 33 & 6 & 6 & 4 & 3 & 27 & 45.00 & 0.25 & 0.358 & 2.9199 \\
\hline 34 & 8 & 4 & 3 & 4 & 31 & 51.67 & 0.25 & 0.264 & 2.0845 \\
\hline 35 & 7 & 9 & 4 & 7 & 45 & 75.00 & 0.25 & 0.341 & 2.7625 \\
\hline 36 & 6 & 2 & 5 & 3 & 29 & 48.33 & 0.00 & 0.010 & 0.0766 \\
\hline 37 & 8 & 7 & 9 & 5 & 43 & 71.67 & 0.05 & 0.034 & 0.2593 \\
\hline 38 & 9 & 9 & 6 & 7 & 45 & 75.00 & 0.25 & 0.364 & $2.9763^{* *}$ \\
\hline
\end{tabular}




\begin{tabular}{|c|c|c|c|c|c|c|c|c|c|}
\hline 39 & 7 & 4 & 3 & 4 & 27 & 45.00 & 0.20 & 0.267 & $2.1100^{*}$ \\
\hline 40 & 5 & 4 & 5 & 2 & 26 & 43.33 & 0.10 & 0.028 & 0.2144 \\
\hline 41 & 9 & 8 & 4 & 6 & 43 & 71.67 & 0.35 & 0.392 & $3.2451^{* *}$ \\
\hline 42 & 2 & 5 & 5 & 2 & 19 & 31.67 & 0.00 & 0.003 & 0.0295 \\
\hline 43 & 8 & 6 & 5 & $\mathbf{3}$ & 30 & 50.00 & 0.30 & 0.265 & $2.0930^{*}$ \\
\hline 44 & 8 & 10 & 8 & 6 & 50 & 83.33 & 0.20 & 0.327 & $2.6352^{* * *}$ \\
\hline 45 & 10 & 7 & 6 & 6 & 43 & 71.67 & 0.25 & 0.293 & 2.3338 \\
\hline 46 & 10 & 10 & 7 & 8 & 53 & 88.33 & 0.25 & 0.073 & 0.5608 \\
\hline 47 & 9 & 8 & 10 & 10 & 54 & 90.00 & -0.15 & -0.051 & -0.3918 \\
\hline 48 & 10 & 10 & 10 & 10 & 59 & 98.33 & 0.00 & 0.001 & 0.0000 \\
\hline 49 & 10 & 9 & 8 & 8 & 53 & 88.33 & 0.15 & 0.055 & 0.4208 \\
\hline 50 & 10 & 9 & 9 & 9 & 54 & 90.00 & 0.05 & 0.035 & 0.2738 \\
\hline 51 & 9 & 7 & 5 & 7 & 43 & 71.66 & 0.20 & 0.283 & $2.2471^{*}$ \\
\hline 52 & 8 & 6 & 7 & 6 & 40 & 66.67 & 0.05 & 0.008 & 0.0665 \\
\hline 53 & 9 & 9 & 9 & 5 & 48 & 80.00 & 0.20 & 0.358 & $2.9199^{* *}$ \\
\hline 54 & 6 & 5 & 4 & 5 & 37 & 61.67 & 0.10 & 0.023 & 0.0182 \\
\hline 55 & 7 & 9 & 6 & 5 & 44 & 73.33 & 0.25 & 0.421 & $3.5347^{* *}$ \\
\hline 56 & 10 & 6 & 6 & 4 & 35 & 58.33 & 0.30 & 0.061 & 0.4699 \\
\hline 57 & 9 & 7 & 7 & 4 & 38 & 63.33 & 0.25 & 0.343 & $2.7809^{* *}$ \\
\hline 58 & 10 & 9 & 8 & 6 & 44 & 73.33 & 0.25 & 0.287 & $2.2817^{*}$ \\
\hline 59 & 9 & 9 & 7 & 8 & 50 & 83.33 & 0.15 & 0.031 & 0.2402 \\
\hline 60 & 10 & 8 & 4 & 5 & 38 & 63.33 & 0.45 & 0.491 & $4.2923^{* *}$ \\
\hline 61 & 6 & 8 & 8 & 6 & 41 & 68.33 & 0.00 & 0.011 & 0.0878 \\
\hline 62 & 7 & 8 & 4 & 3 & 32 & $\mathbf{5 3 . 3 3}$ & 0.40 & 0.257 & $2.0252^{*}$ \\
\hline 63 & 10 & 9 & 10 & 7 & 53 & 88.33 & 0.10 & -0.499 & -4.3958 \\
\hline 64 & 8 & 10 & 9 & 8 & 49 & 81.67 & 0.05 & 0.018 & 0.1397 \\
\hline 65 & 9 & 5 & 3 & 8 & 39 & 65.00 & 0.15 & 0.023 & 0.1756 \\
\hline 66 & 9 & 10 & 5 & 8 & 48 & 80.00 & 0.30 & 0.461 & $3.9563^{* *}$ \\
\hline 67 & 9 & 5 & 8 & 8 & 40 & 66.67 & 0.10 & 0.011 & 0.0854 \\
\hline 68 & 10 & 8 & 8 & 8 & 52 & 86.67 & 0.10 & 0.035 & 0.2689 \\
\hline 69 & 10 & 8 & 8 & 8 & 48 & 80.00 & 0.10 & 0.037 & 0.2870 \\
\hline 70 & 8 & 8 & 8 & 8 & 43 & 71.67 & 0.00 & -0.004 & -0.0312 \\
\hline 71 & 10 & 8 & 5 & 6 & 40 & 66.67 & 0.35 & 0.429 & $3.6169^{* *}$ \\
\hline 72 & 10 & 7 & 4 & 3 & 34 & 56.67 & 0.50 & 0.532 & $4.7849^{* *}$ \\
\hline 73 & 8 & 7 & 7 & 5 & 39 & 65.00 & 0.15 & 0.039 & 0.3040 \\
\hline 74 & 9 & 7 & 7 & 6 & 42 & 70.00 & 0.15 & 0.027 & 0.2099 \\
\hline 75 & 5 & 3 & 3 & 2 & 21 & 35.00 & 0.10 & 0.042 & 0.3203 \\
\hline 76 & 8 & 6 & 7 & 7 & 47 & 78.33 & 0.00 & 0.003 & 0.0248 \\
\hline 77 & 8 & 8 & 7 & 8 & 44 & 73.33 & 0.05 & 0.007 & 0.0539 \\
\hline 78 & 9 & 6 & 4 & 2 & 35 & 58.33 & 0.45 & 0.068 & 0.5209 \\
\hline 79 & 6 & 7 & 6 & 4 & 36 & 60.00 & 0.15 & 0.026 & 0.2021 \\
\hline 80 & 9 & 6 & 4 & 2 & 33 & 55.00 & 0.45 & 0.296 & $2.3600^{*}$ \\
\hline 81 & 10 & 9 & 7 & 8 & 47 & 78.33 & 0.30 & 0.332 & $2.6841^{\text {** }}$ \\
\hline
\end{tabular}




\section{Practicability of the test}

Each of the 39 items in the knowledge test was administered to the respondents in Telugu language and their responses were recorded in the form of correct or incorrect answers. The correct answer was assigned with a weightage of " 1 " and a weightage of " 0 " was assigned to incorrect answer. The total score of correct answers given by an individual respondent will be knowledge of that particular respondent. Later the respondents will be categorized into different groups (low, medium and high) based on the mean and standard deviation.

\section{References}

Bloom B S, Engelhardt M, Frust E, Hill, W and Rathwal, D.R. 1956. Taxonomy of educational objectives, The cognitive domain, Orient Longmans, New York.

Garrett, H.E. 1966. Statistics in psychology and education. David McKay company Lnc.and Longman Group Ltd., New York.

Gonard, H.S.1948. Characteristics and uses of items analysis of data. Psychological monograph

\section{How to cite this article:}

Srividya Rani, N., T. Lakshmi, P. V. Sathya Gopal, N. Vani and Ravindra Reddy, B. 2020. Standard Test to Measure Knowledge of Groundnut Farmers on Sustainable Cultivation Practices. Int.J.Curr.Microbiol.App.Sci. 9(01): 169-175.

doi: https://doi.org/10.20546/ijcmas.2020.901.019 